\title{
Recording of Motor Unit Potentials Count of Middle Trapezius in Children with Rounded Back
}

\author{
ALAA M. AL QAZZAZ, M.Sc.*; KHALED A. OLAMA, Ph.D.** and RADWA S. ABDUL RAHMAN, Ph.D.** \\ The Departments of Physical Therapy* and Physical Therapy for Pediatrics**, Faculty of Physical Therapy, Cairo University
}

\begin{abstract}
Background: Poor posture is unfortunately wide spreading not only among adults but also among children.

Aim of Study: To detect the effect of rounded back posture on the Motor Unit Potentials (MUPs) count of middle trapezius.

Patients and Methods: The right and left trapezius motor unit potentials countof 15 normal children $(8.64 \pm 0.77$ years $)$ were compared with 15 children with rounded back $(8.92 \pm 0.73$ years) using electromyography apparatus (EMG).

Results: There was a significant increase in the right trapezius motor unit count of the rounded back group compared with that of the normal group ( $p=0.02$ ). There was no significant difference in the left trapezius motor unit count between the normal and the rounded back groups $(p=0.25)$.
\end{abstract}

Conclusion: Rounded back posture affects the middle trapezius motor unit potential count.

Key Words: Rounded back-MUPs - Middle trapezius $E M G$.

\section{Introduction}

"POSTURE" is a motor habit shaped on a specified morphological and functional background. Based on this point of view, posture is an indicator of the mechanical efficacy of the kinetic sense, as well as muscular balance and neural muscular coordination [1]. For an efficient muscle action and good positioning of the thoracic and abdominal organs, an ideal position in required [2].

The transition to more sedentary lifestyle in a world of sedentary behaviours (e.g. several hours of sitting during learning at school and at home, watching TV and using PC), and the reduction in physical activity in favour of extra activities performed mostly in sitting positions, such as learning

Correspondence to: Dr. Alaa M. Al Qazzaz, The Department of Physical Therapy, Faculty of Physical Therapy, Cairo University foreign languages or playing musical instruments might lead to obesity. All of these changes are negative factors that lead to the development of postural disorders [3].

Rounded back, also called kyphosis is an anteroposterior curvature in which the convexity is directed posteriorly. Rounded back is commonly present in children and adolescents as a result of faulty posture especially in teenage girls as her skeletal growth is faster than her muscular growth [4].

Electromyography is the usage of electrodes to record the electrical activity within a muscle [5] Motor Unit Action Potentials are produced by the summation of individual muscle fibres innervated by the same motor neurone and are activated by voluntary muscle contraction [6].

\section{Patients and Methods}

The purpose of the study was to detect the changes in the Motor Unit Potentials (MUPs) count of the middle trapezius in children with rounded back. This study was conducted from March 2019 till September 2019 at the Physical Therapy Department of a Medical Unit of the Ministry of Health in the fifth settlement, Cairo district. The study was conducted based on the ethical committee approval of the Faculty of Physical Therapy, Cairo University, Egypt. A written consent form was obtained from the participant's caregiver(s) before starting the study.

\section{Patients:}

Thirty children of both gender, 15 normal and 15 children with rounded back, were included in this study. 
Inclusion criteria: Their age ranged from 7-10 years and all the children had normal development.

Exclusive criteria: Present or history of any musculoskeletal, cardiopulmonary or neurogenic disorders or being athletic.

\section{Material:}

For screening:

"BMI":

- Body height: $(0.1 \mathrm{~cm})$ was measured using a stadiometer.

- Body weight: $(0.1 \mathrm{~kg})$ was measured using a portable digital scale.

From these measurements, the child's BMI was calculated as body weight divided by squared height $\left(\mathrm{kg} / \mathrm{m}^{2}\right)$ [7].

\section{"Plumb line":}

Plumb line is a method that involves free hanging of a rope with a weight at its end as a reference standard, which represents the pathway of the line of gravity [8]

Typically, from the sagittal view, the line of gravity passes through the ear lobe and the centre of the shoulder, and slightly anterior to the lateral malleolus [9].

Children stood barefoot topless or wearing cut tops behind the plumb line for shoulder visualization. To assess the child's posture, circular adhesive dots were placed over right acromion process of shoulder. Children were instructed to standcomfortably, in their "normal, loose, or habitual" posture placing their weight evenly on both feet,with knees straight, hands at their sides, and with their eyeslooking forward.

Children were categorized as follow:

- If the robe passes through the child's shoulder joint ínormal (control group).

- If the robe passes posterior to the child's shoulder joint írounded (study group).

For electromyography analysis:

"Electromyography study device (EMG)":

Neuro EMG apparatus from Neurosoft $\odot$ was used for the electromyography study. Surface EMG and intramuscular EMG signals are recorded by non-invasive electrodes and invasive electrodes, respectively. The basic method for understanding the human body's behaviours under normal and pathological conditions is provided by the recording of EMG signals [10].
The following procedure was done on the right and left middle trapezius:

- The child was asked to take off the shirt and sit comfortably on a chair.

- An earth electrode was placed over the contralateral shoulder.

- Beforesurface electrodes application,the skin was rubbed with alcohol toreduce skin impedance.

- Two surface recording electrodes were placed, $0.5 \mathrm{~cm}$ apart, medial to the medial edge of the right scapular spine to detect the middle trapezius activity.

- The child was asked to relax completely to record the spontaneous activity of middle trapezius.

- Then the extension MVIC test was performed: Each child was seated with thearm at $30^{\circ}$ abduction, elbow fully extended, and thumb towardthe body; arm extended as resistance applied over the distalforearm [11].

\section{Results}

\section{Normal group:}

Fifteen normal children were included in this group. Their mean \pm SD age, weight, height and BMI were $8.64 \pm 0.77$ years, $27.3 \pm 8.2 \mathrm{~kg}, 1125.85 \pm$ $9.15 \mathrm{~cm}$ and $16.84 \pm 2.73 \mathrm{~kg} / \mathrm{m}^{2}$ respectively (Table $1)$.

\section{Rounded back group:}

Fifteen children with rounded back were included in this group. Their mean \pm SD age, weight, height and BMI were $8.92 \pm 0.73$ years, $26.77 \pm$ $3.85 \mathrm{~kg}, 128.28 \pm 7.53 \mathrm{~cm}$ and $16.18 \pm 1.05 \mathrm{~kg} / \mathrm{m}^{2}$ respectively (Table 1 ).

Comparing the general characteristics of the subjects of both groups revealed that there was no significance difference between the two groups in the mean age, weight, height andBMI $(p>0.05)$.

Comparison of motor unit count between the normal and rounded back groups:

Right trapezius:

The mean value of right trapezius motor unit count of the normal group was $4.73 \pm 1.9$ and that of the rounded back group was $6.33 \pm 1.75$. The mean difference between both groups was -1.6. There was a significant increase in the right trapezius motor unit count of the rounded back group compared with that of normal group ( $p=0.02)$ (Table 2). 


\section{Left trapezius:}

The mean value of left trapezius motor unit count of the normal group was $4.6 \pm 2$ and that of the rounded back group was $5.4 \pm 1.8$. The mean difference between both groups was 0.8 . There was no significant difference in the left trapezius motor unit count between the normal and the rounded back groups $(p=0.25)$.

Table (1): Comparison of the mean age, weight, height and BMI between the normal and rounded back groups.

\begin{tabular}{llcllll}
\hline & $\begin{array}{c}\text { Normal group } \\
\mathrm{X} \pm \mathrm{SD}\end{array}$ & $\begin{array}{c}\text { Rounded back group } \\
\mathrm{X} \pm \mathrm{SD}\end{array}$ & $\mathrm{MD}$ & $\begin{array}{c}t- \\
\text { value }\end{array}$ & $\begin{array}{c}p \text { - } \\
\text { value }\end{array}$ & Sig. \\
\hline Age (years) & $8.64 \pm 0.77$ & $8.92 \pm 0.73$ & -0.28 & -1.01 & 0.31 & $\mathrm{NS}$ \\
Weight $(\mathrm{kg})$ & $27.3 \pm 8.2$ & $26.77 \pm 3.85$ & 0.53 & 0.22 & 0.82 & $\mathrm{NS}$ \\
Height $(\mathrm{cm})$ & $125.85 \pm 9.15$ & $128.28 \pm 7.53$ & -2.43 & -0.79 & 0.43 & $\mathrm{NS}$ \\
$\mathrm{BMI}\left(\mathrm{kg} / \mathrm{m}^{2}\right)$ & $16.84 \pm 2.73$ & $16.18 \pm 1.05$ & 0.66 & 0.86 & 0.39 & $\mathrm{NS}$ \\
\hline$\overline{\mathrm{X}}:$ Mean. & \multicolumn{3}{c}{$p$-value : Probability value. } & & \multicolumn{2}{c}{$t$-value: Unpaired $t$-value. } \\
$\mathrm{MD}:$ Mean Difference. & $\mathrm{SD} \quad$ : Standard Deviation. & NS : Non Significant.
\end{tabular}

Table (2): Comparison of motor unit count between the normal and rounded back groups.

\begin{tabular}{|c|c|c|c|c|c|c|}
\hline Motor unit count & $\begin{array}{l}\text { Normal group } \\
\quad X \pm S D\end{array}$ & $\begin{array}{l}\text { Rounded back group } \\
\quad X \pm S D\end{array}$ & MD & $\begin{array}{c}t- \\
\text { value }\end{array}$ & $\begin{array}{c}p- \\
\text { value }\end{array}$ & Sig. \\
\hline Right trapezius & $4.73 \pm 1.9$ & $6.33 \pm 1.75$ & -1.6 & -2.38 & 0.02 & $\mathrm{~S}$ \\
\hline Left trapezius & $4.6 \pm 2$ & $5.4 \pm 1.8$ & -0.8 & -1.15 & 0.25 & NS \\
\hline
\end{tabular}

\section{Discussion}

The purpose of the study was to detect the Motor Unit Potentials (MUPs) count of the middle trapezius in children with rounded back and compare it with that of normal children.

The postural deficiencies are numerous, especially in early school aged children and the most advantageous way to prevent and correct it in physical education and sports activities. If detected early, before producing structural changes of tissues, in most cases postural deficiencies can be corrected and even prevented through normal physical education programs [12]

In a similar study, changes in the EMG Median Frequency (MF) of the neck-shoulder muscles were examined in symptomatic and asymptomatic female office workers when they were exposed to three physical stressors. Case Group consistently showed trends for higher MF than the control group. The consistent group differences in MF, suggested different muscle recruitment strategies between symptomatic and asymptomatic office workers. These results implied that symptomatic individuals had altered motor control, which may have important implications in understanding the etiology of work-related musculoskeletal disorders [12].
Another study compared the electromyographicactivity of the trapezius in healthy adult controls to a neck pain group with poor scapular posture during the performance of a functional typing task. A scapular postural correction strategy was used to correct scapular orientation in the neck pain group and electromyographic recordings were repeated. During the typing task, the neck pain group generated greater activity in the middle trapezius and less activity in the lower trapezius than the control group. Following correction of the scapula, activity recorded by the neck pain group was similar to the control group for the middle and lower portions. These findings indicate that a scapular postural correction exercise may be effective in altering the distribution of activity in the trapezius to better reflect that displayed by healthy individuals [14]

\section{Conclusion:}

On the bases of the presented data, it is concluded that having forward shoulders can lead to changes in the middle trapezius MUPs count. Thus, it's derived thatforward shoulder posture may become a potential risk factor evoking the various shoulder disorders.

The changes in the shoulder muscles activity due to forward shoulder posture may be one of the 
main contributions for evoking many shoulder disorders later in life, such as impingement syndrome, winging or tipping scapula, shoulder joint arthritis andtendonitis, and myofascial pain syndrome [15].

Accordingly, early detection of any abnormalities and its management is essential to prevent lifelong problems that could persist to adulthood.

\section{References}

1- LATALSKI M., BYLINA J., FATYGA M., REPKO M., FILIPOVIC M., JAROSZ M.J., BOROWICZ K.B., MATUSZEWSKI L. and TRZPIS T.: Risk factors of postural defects inchildren at school age. Ann. Agric. Environ. Med., 20 (3): 583-7, 2013.

2- PENHA P., JOO S., CASAROTTO R., AMINO C. and PENTEADO D.: Postural assessment of girls between 7 to 10 years of age, 2005.

3- BRZEK A., DYRDA B., NOWOTNY-CZUPRYNA O. and JACHACZ-LOPATA M.: Postural defects prevention programme as the exemplification of actions in the scope of health promotion in early school education-an action research perspective. New Educ. Rev., 24 (2): 194-204, 2011.

4- CASE-SMITH J. and CLIFFORD J.: 'An Overview of Occupational Therapy for Children', Occupational Therapy for Children. 6th ed. pp. 154, 2010.

5- FORS S.: Neuromuscular manifestations of hypothyroidism in dogs. Svensk Veterinartidning, (14) pp.: 11-7, 2006.

6- BERTORINI T.: 'Neurologic Evaluation and Ancillary Tests', Neuromuscular Case Studies, pp. 27-76, 2008.
7- D'HONDT E., DEFORCHE B., GENTIER I., VERSTUYF J., VAEYENS R., BOURDEAUDHUIJ I. and LENOIR M.: A longitudinal study of gross motor coordination and weight status in children. Obesity, 22 (6): 1505-11, 2014.

8- WILMARTH M.A. and HILLIARD T.S.: Measuring head posture via the craniovertebral angle. Orthopedic Physical Therapy Practice, 14 (1): 13-5, 2002.

9- KENDALL F.P., McCREARY E.K. and PROVANCE P.G.: Muscles tests and functions. São Paulo: EditoraManole; 1995.

10- CHOWDHURY R., REAZ M., ALI M., BAKAR A., CHELLAPPAN K. and CHANG T.: Surface Electromyography Signal Processing and Classification Techniques. Sensors, 13 (9): pp. 12431-66, 2013.

11- GINN K., HALAKI M. and CATHERS I.: Revision of the Shoulder Normalization tests is required to include rhomboid major and teres major. Journal of Orthopaedic Research, 29 (12): pp. 1846-9, 2011.

12- COSMA G., ILINCA I., RUSU L., NANU C. and BURILEANU A.: Physical exercise and its role in a correct postural alignment. DiscobolulPhysEduc Sport Kinetother J., 11, 1, 39: 58-64, 2015.

13- SZETO G., STRAKER L. and O'SULLIVAN P.: EMG median frequency changes in the neck-shoulder stabilizers of symptomatic office workers when challenged by different physical stressors. Journal of Electromyography and Kinesiology, 15 (6): pp. 544-55, 2005.

14- WEGNER S., JULL G., O'LEARY S. and JOHNSTON V.: The effect of a scapular postural correction strategy on trapezius activity in patients with neck pain. Manual Therapy, 15 (6): pp. 562-6, 2010.

15- YOO W.: Comparison of Shoulder Muscles Activation for Shoulder Abduction between Forward Shoulder Posture and Asymptomatic Persons. Journal of Physical Therapy Science, 25 (7): pp. 815-6, 2013.

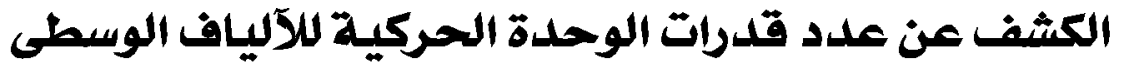

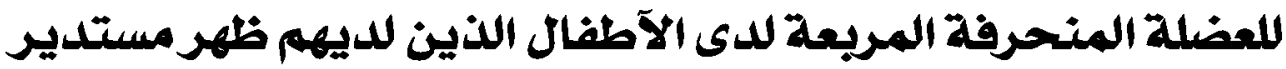

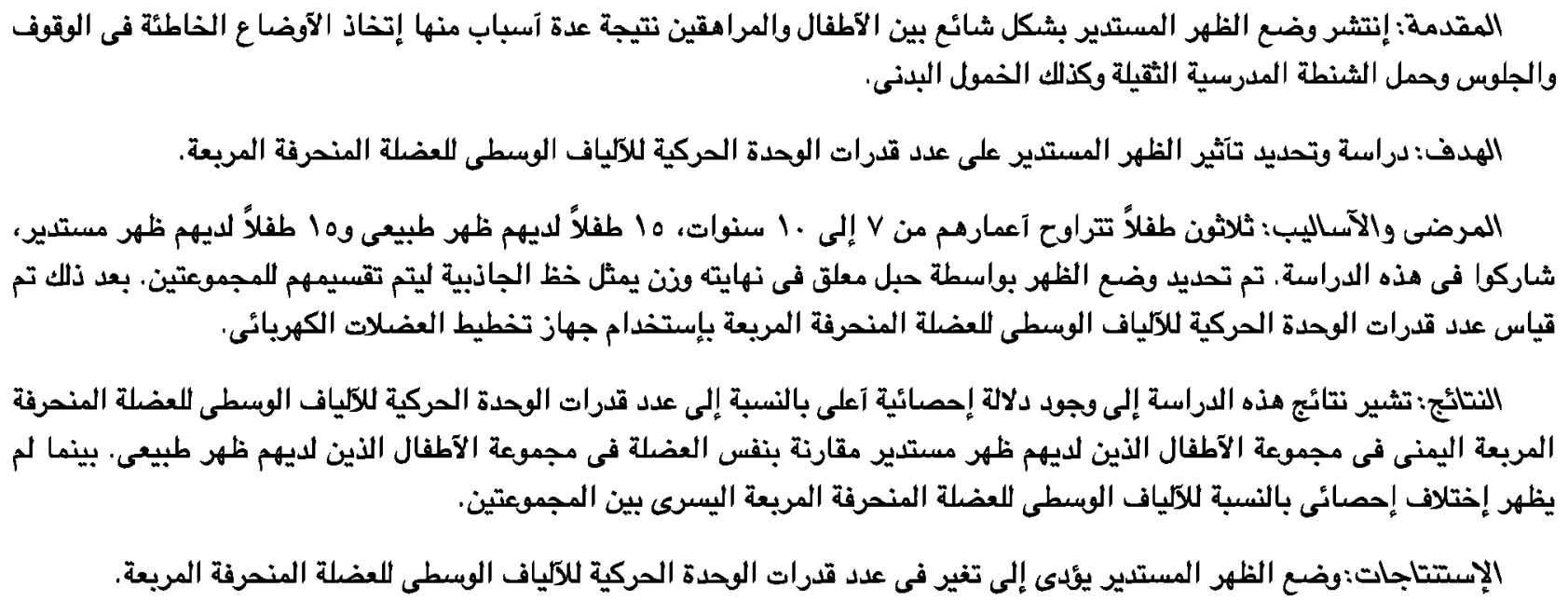

